\title{
REFLEXIONES EN TORNO A ANTONIO GRAMSCI Y ALGUNOS TEMAS DE LA CUESTIÓN MERIDIONAL
}

\section{REFLECTIONS AROUND ANTONIO GRAMSCI \\ AND SOME ISSUES OF THE SOUTHERN QUESTIONS}

\author{
MARTÍN RÍOS-LÓPEZ* \\ Mg. en Filosofía \\ Universidad de Playa Ancha, Chile
}

Artículo recibido el I6 de diciembre de 2020; aceptado el 25 de diciembre de 2021.

"martin.rios@upla.cl

https://orcid.org/o000-000I-5756-3240

Cómo citar este artículo:

RÍOS LÓPEZ, M. "Reflexiones en torno a Antonio Gramsci y algunos temas de la cuestión Meridional” en Palabra y Razón. Revista de Filosofía, Teología y Ciencias de la Religión. No 20 DICIEMBRE 202I, pp. IO-32 https://doi.org/I0.29035/pyr.20.IO 


\title{
RESUMEN
}

La filosofía de Gramsci posee una actualidad y vigencia que el paso del tiempo no ha sido capaz de descomponer. El tema de la llamada cuestión meridional posee una importancia ya que permite comprender su condición intelectual revolucionario, las categorías de teoría de la praxis y la importancia de la historia. A los tiempos nuevos le es necesario un filósofo nuevo, que sea capaz de entender el tiempo presente para orientar y guiar al triunfo a las fuerzas políticas revolucionarias.

Palabras claves: hegemonía / la cuestión Meridional / marxismo gramsciano / filosofía de la praxis

\begin{abstract}
Gramsci's philosophy has a validity and currency that time has not been able to break down. The theme of "the southern question" is important because it allows us to understand his revolutionary intellectual condition, the categories of the theory of praxis and the importance of history. The new times need a new philosopher, who is able to understand the present time in order to guide the revolutionary political forces to triumph.
\end{abstract}

Keywords: hegemony / hhe southern question / gramscian marxism / philosophy of praxis 


\section{Consideraciones preliminares}

Las peculiaridades que nutren el núcleo central de su pensamiento, hacen de Antonio Gramsci un referente filosófico fundamental en la historia de la filosofía y la política occidental durante un largo trayecto del siglo XX. Peculiaridades que, muy posiblemente, mantienen su vigencia analítica y que se acrecientan vigorosamente hasta nuestros días. Es así que, en esta convicción, nos parece interesante rescatar alguna de sus reflexiones con el fin de robustecer la batería teórica y, de ese modo, intentar comprender con mayor exactitud nuestra época que no deja de ser, así como la del propio Gramsci, una época moderna. Si esto es así, entonces conviene no olvidar una primera afirmación: que la obra del pensador sardo se encuentra siempre de cara al presente. Esta afirmación, formulada en un tono de advertencia, a pesar que pueda parecer llena de candidez, contiene, sin embargo, una consideración que difícilmente se puede desechar de buenas a primeras por una falta de lógica. La afirmación, si se quiere, también se podría formular en una óptica distinta, a saber, que cada texto existe y se exige en un diálogo con su contexto, histórico, político y cultural. En tal sentido, digamos que Gramsci es absolutamente consciente que la historia de la filosofía es capaz de reflejar sólo de manera parcial los problemas que se encuentran latentes o bien que surgen del proceso de desarrollo de la cultura en general $^{1}$. Esto significa que se encuentra exigida en su tiempo, por tanto, se ve en la necesidad de apostar y de dialogar problemáticamente con los acontecimientos, interpretándolos, y, sobre todo, ofreciendo un diagnóstico que permita subvertir el estado de cosas de lo político. Pero no sólo eso, sino que también en la convicción de que es necesario producir un razonamiento con la potencia suficiente que permita abrir un espacio y enfrentarse 'con' y 'contra' el sentido común, y, contra los desafíos que condicionan (y tensan) su momento histórico. Esto, como una estrategia que permitirá disponer las condiciones teóricas para enfrentar los acontecimientos, de forma tal, que le de la posibilidad para acreditarse como una reflexión contemporánea a su época. Una contemporaneidad que sería conveniente entender necesariamente como una vocación intempestiva, puesto que la filosofía es siempre parasitaria del presente $y$, por tanto, los insumos materiales del pensador se encuentran en esa secreta inclinación por la contingencia, la inmanencia -esto es-, en la urgencia que exige atender la forma actual de los acontecimientos históricos, políticos y culturales.

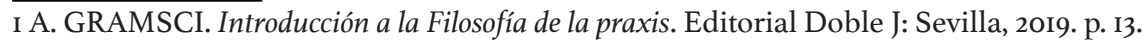


Siendo esto así, no sería descabellado sostener que el horizonte de la reflexión gramsciana aspirara, entre otras cosas, a sacudir los letargos propios de su época al propiciar una lectura a contra corriente de los usos habituales, permitiendo de esa manera una superación tanto de "la religión y del sentido común" ${ }^{2}$ así como también de los marxismos hegemónicos de orientación stalinista que para 1926 estaban guiando los destinos de la revolución rusa y por ende inspirando las directrices generales por las cuales habrían de conducirse los destinos de los diversos partidos comunistas alrededor del mundo durante una buena parte del siglo XX. En tal caso, tampoco resulta disparatado convenir que el eco de los análisis aportados por Marx y Engels en El Manifiesto del Partido Comunista en torno a que "Las ideas dominantes de una época fueron siempre las ideas de la clase dominante"3 han sido un faro que inspiró la propia convicción de sus ideas. En su estudio sobre Gramsci, Antonio Santucci, y a propósito de lo que estamos señalando, aporta a nuestra discusión la siguiente cita que proviene de Los cuadernos de la Cárcel: "La filosofía de una época histórica no es pues otra cosa que la masa de variaciones que el grupo dirigente ha logrado determinar en la realidad precedente: historia y filosofía son inescindibles en este sentido, formando un bloque"4.

Con lo dicho hasta acá, la pretensión gramsciana parece hacerse un poco más nítida. La intempestividad del pensamiento ha de conjurar, si quiere ser auténtica, una cita que permita una reflexión crítica con todas aquellas fuerzas que configuran la cartografía política del presente. Y, por cierto, hemos de ser conscientes que ese encuentro no puede darse en la comodidad que el interés del momento hegemónico impone. Escribir (hacer filosofía) será entonces una forma de hacer cuentas con la historia. Ahora, que mejor manera de hacerlo cuando "discute y polemiza con sus contemporáneos a partir de la interpretación de acontecimientos políticosociales recientes o en curso, y desde ahí sugiere una reconstrucción de los usos de la palabra a lo largo de la historia"5.

Siguiendo estas líneas de análisis, ya podríamos encontramos en condiciones de afirmar que todos los textos poseen una historia (intenciones, pasiones o deseos) que les orientan. Algunas rozan lo anecdótico. Otras lo cómico, lo trágico, o, incluso también, lo indignante y hasta lo sorprendente. En el caso de las reflexiones gramscianas

\footnotetext{
2 A. GRAMSCI. Introducción a la Filosofía de la praxis... p. 7.

3 K. MARX - F. ENGELS. El Manifiesto del Partido Comunista. Biblioteca Nueva: Madrid, 2007. p. 70. 4 A. SANTUCCI. Gramsci. LOM: Santiago de Chile, 2005, p. 8I.

5 F. FERNÁNDEZ BUEY. Leyendo a Gramsci. El viejo Topo: Madrid, 20oI, p. 97.
} 
contenidas en Algunos temas de la cuestión meridional, esta advertencia no escapa en modo alguno a su imperio ni son una excepción a la regla. Contemos, pues, brevemente su historia. Lo primero que debemos saber es que este texto, tal cual como lo conocemos, tiene su fuente en un manuscrito conservado en el 'Archivo' del Partido Comunista Italiano $(\mathrm{PCI})^{6}$. Esta versión inicial del documento gramsciano fue publicada por primera vez en la ciudad de París durante el mes de enero de 1930 en las páginas de la revista Lo Stato Operaio (Estado Obrero). Como antecedente resulta importante señalar que la revista del Partido Comunista Italiano (PCI) fue fundada por Palmiro Togliatti en Turín y tuvo -en su primera época- una publicación periódica semanal hasta el año I925. Luego de ese receso forzado por las circunstancias políticas del momento histórico, la revista logró retomar sus actividades de difusión política y se comenzó a publicar nuevamente, pero esta vez en la ciudad de París, entre los años 1927 y 1939. Sin embargo, el desarrollo de las actividades y la difusión se vieron nuevamente interrumpidas como resultado del estallido de la Segunda Guerra Mundial en el mes de septiembre de 1939 con la invasión de la Alemana Nazi a Polonia. Posteriormente, y en lo que se podría considerar como un tercer ciclo, la revista retornó a la escena pública y política, pero en esta oportunidad bajo la iniciativa encabezada por Guissepe Berti en la ciudad de Nueva York entre los años I940 y 1943 donde para entonces éste ya se había radicado ${ }^{7}$. Por cierto, valga señalar que la revista en su edición parisina también circuló -clandestinamente, eso sí- en la Italia fascista de Mussolini.

En aquella publicación de 1930, los editores hacían la advertencia al potencial público que éste era un texto 'incompleto' e 'inacabado'. Y, como se sabe, incluye una nota a pie de página que, a modo de advertencia, señala sumariamente, a razón de lo dicho, que "El escrito no estaba completo y probablemente hubiese sido retocado todavía, aquí o allí, por el autor. Lo reproducimos sin ninguna corrección, como el mejor documento de un pensamiento político comunista, incomparablemente profundo, fuente, original, rico en desarrollos más amplio"s.

Con ello se pone en antecedentes al lector de forma explícita que este un escrito forjado al calor de los acontecimientos históricos y que no había sufrido posteriores revisiones o correcciones por parte de su autor.

\footnotetext{
6 Este manuscrito fue encontrado por Camila Ravera entre las cartas que Gramsci tuvo que abandonar al momento de su arresto.

$7 \mathrm{Al}$ término de la Segunda Guerra Mundial, y para cuando Italia ya había abrazado su destino republicano, se desempeñó como Diputado del Partido Comunista Italiano desde 1948 hasta 1958 y posteriormente como Senador desde 1958 hasta 1963.

8 A. GRAMSCI. La cuestión meridional. Quadratta: Buenos Aires, 2002, p. 75.
} 
Por tanto, es un texto que guarda un cierto carácter de provisionalidad, o, de primeras notas indagatorias en limpio de un análisis que se prometiera a sí mismo un desarrollo a futuro. Fue redactado, como sabemos, en 1926 y poco antes de que fuera detenido por orden del Duce y acusado bajo los cargos de actividad conspirativa, apología del delito e incitación al odio de clases9. El objetivo por parte del régimen fascista de Mussolini era un tanto evidente, silenciar a uno de los teóricos y activistas más importantes. Fue así que, en 1928 y con apenas treinta y siete años, es condenado por el Tribunal especial de Defensa del Estado a pasar los próximos veinte años en prisión. El fiscal que logró la condena de Gramsci se regocijaba a viva voz del triunfo, celebrando que a partir de ese momento se había conseguido apagar ese cerebro. Una celebración en falso puesto que igualmente pudo desarrollar una intensa actividad intelectual que dio como resultado esos treinta y dos cuadernos en los que se esmeró a analizar la realidad cultural e histórica por medio de las diferentes reflexiones, artículos y notas temáticas.

Por otra parte, también resulta importante atender al hecho de que, como muy acertadamente recuerda Mario García Bonafe, las reflexiones gramscianas contenidas en Algunos temas de la cuestión meridional son el resultado de una larga reflexión que ocupó la preocupación intelectual del pensador sardo desde I9I6 a I926, y que tenían, como objetivo último, pensar "La relación entre revolución y cuestión meridional" Io. Por tanto, esta preocupación gramsciana por 'la cuestión meridional', cabe comprenderla, no como una discusión aislada ni tampoco espontánea en el itinerario de su pensamiento. Es, por el contrario, un problema que ocupó un tiempo más que razonable. Incluso más, podría llegar a afirmarse que este escrito contiene en estado germinal una serie de preocupaciones, temas o categorías fundamentales para el conjunto de su pensamiento. Sobre la condición provisional del texto era conciente el propio Gramsci, y así se lo hace ver con claridad a Tatiana Schucht -su cuñada-, en una epístola que data del ig de marzo de 1927 a quien le señala que:

Una investigación acerca de la formación del espíritu público en Italia el siglo pasado; dicho de otro modo, una investigación acerca de los intelectuales italianos, sus

9 Para más detalles sobre la situación y el contexto político e histórico en que se vio involucrado Antonio Gramsci en ese período de su vida, resulta altamente recomendable tener a vista la notable "Nota editorial" que han ofrecido Mauro Lucio Maldonado, Gary Pinto y Víctor Portugal en el libro Gramsci Catálogo de Los Cuadernos de la Cárcel, pp. I-I6.

Io M. GARCÍA BONAFE. "Gramsci y la cuestión meridional" en Revista de Historia Moderna. 4 (1975), p. 29I. Disponible en: https://roderic.uv.es/handle/I0550/34075 
orígenes, sus ocupaciones según las corrientes de cultura, sus diversos modos de pensar, etc. Tema sugestivo en sumo grado, dada la imposibilidad absoluta de disponer de la mole inmensa de material que sería necesaria. ¿Recuerdas mi rápido y superficial escrito acerca de la Italia meridional y la importancia de B. Croce? Pues bien, querría desarrollar ampliamente la tesis que apunté allí, desde el punto de vista 'desinteresado', für ewig'.

Al describir ese trabajo como "rápido y superficial”, y, por extensión, quizás de buena parte de lo escrito hasta ese momento, Gramsci parece sincerar el propósito político alentaba sus letras. En tal caso, la coyuntura se debe a que éstos atienden la problemática social, política o cultural del momento, son, diríamos, escritos para el día. De ahí entonces es que se hace comprensible la tentativa de marchar hacia una escritura marcada por el desinterés, cuestión que no es otra cosa más que dejar de escribir bajo el imperativo 'desde' y 'para' la pragmática cuyuntural. De esa forma se puede explicar el carácter de provisorio o la urgencia que revisten a los mismos. Pero una vez que ha cambiado su estatus de hombre que goza de la libertad a uno que tiene que comenzar a sobrellevar la situación de presidiario en las cárceles del fascismo mussoliniano, también cambia el público objetivo a quien pretende llegar con sus reflexiones. Esto significa, pasar de una escritura que atiende a la contingencia a otra nueva que se permita quedar 'para siempre' (für ewig). Inspirado en ese horizonte de necesidad, es que "Gramsci quería escribir ya no para un público inmediato y para lograr efectos inmediatos sobre un tema condicionado por las circunstancias externas también inmediatas, sino para lectores ideales cuya existencia tiene que presumir, es decir, sin saber siquiera si estos lectores van a llegar a existir" ${ }^{\prime 2}$. En tal caso se puede afirmar que el objetivo de la escritura gramsciana, a partir de esa experiencia de cárcel, se afirma bajo un nuevo carácter que se interesa esta vez por un sujeto que se encuentra el horizonte del por-venir. Le interesa encontrarse, esto es, formar y capacitar a ese sujeto futuro que, aun trasciendo la contingencia, no se desentiende de las condiciones y la responsabilidad que en la exigencia política dan forma a su presente.

Por último, nos parece importante también delinear brevemente otra difucultad que implica el abordaje de estos Algunos temas de la cuestión meridional. Junto con el hecho que es un texto que se encuentra en estado puro, -como ya hemos indicado- para el lector de habla 
hispana, el acceso a las fuentes, reviste todo un desafío. Primero porque, ahora mismo, contamos con dos versiones. Pero conviene no equivocarse. Por un lado, contamos con la cánonica traducción de Manuel Sacristán -quien, para muchos, es una de las mejores cabezas del marxismo español-, en la editorial Siglo XXI (y, desde 2013, también disponible bajo el sello editorial $A k a l$ ), la que se encuentra recogida en un libro antológico. A esto habría que sumarle el hecho que lo que nos ofrece Sacristán son unos fragmentos. Algo común para el caso de una antología. Contamos también con una edición argentina de la Editorial Quadrata con una traducción de Amalia Bastidas del año 2002. Una edición de difícil acceso, pero al menos, el fragmento que circula por la web nos permite apreciar un índice extenso que supera con creces con lo que se cuenta en la obra anterior.

\section{Gramsci y la cuestión meridional}

Para dar cuenta de Antonio Gramsci y su interés en la llamada cuestión meridional, es perentorio encontrarse al corriente de una serie de antecedentes preliminares en torno a su persona como también al contexto histórico y político en el cual se dan estos asuntos. En tal caso, tanto Emilio Corbière como Francisco Fernández Buey son quienes permiten hacernos con un semblante intelectual de la figura de Gramsci. Cuando Corbière, al afirmar por un lado que "(...) fue un intelectual revolucionario, no un académico"13 quiere destacar su profunda vocación por la praxis que lo aleja del semblante del teórico clásico, así como también del típico catedrático universitario de la época. En esa misma línea argumentativa es que Fernández Buey sostiene que "Gramsci no era un político profesional como otros dirigentes socialistas no tampoco un dirigente sindical, sino más bien un periodista culto (para la época), con formación universitaria, que hizo suya la causa de la vanguardia del proletariado"I4. Atendiendo a estas particularidades se podría decir que Gramsci es una figura distópica, esto es, un pensador o un tipo de intelectual que se resiste a una clasificación corriente y al uso de manuales. Si bien llegó a cursar estudios universitarios, e incluso en algún momento hubo visos de una prominente carrera académica, nada de eso llegó a concretarse. En torno a ese asunto, Antonio Santucci es quién, en su libro dedicado al pensador sardo, no olvida que Gramsci se vio obligado por la falta de condiciones económicas a "abandonar

I3 E. CORBIÈRE. "Antonio Gramsci” en CEME. Centro de estudios Miguel Enríquez. Archivos Chile. (s.f.). Disponible en: http://www.archivochile.com/Ideas_Autores/gramscia/s/gramscisobreooo2. pdf

I4 F. FERNÁNDEZ BUEY. Leyendo a Gramsci... p. I04. 
los estudios universitarios sin haberse titulado"15. Si bien su experiencia universitaria se vio interrumpida al punto que no llegó a concluir estudios de ninguna índole, eso no impidió que desarrollara sus inquietudes como un intelectual comprometido con su época. Y más aún, que al día de hoy pueda ser considerado como uno de los pensadores con mayor influencia en las reflexiones políticas en torno a los acontecimientos suscitados tanto en América Latina como en Europa a lo largo de la segunda mitad del siglo veinte. Entonces, siendo esto así, ya se puede convenir que no hay una relación necesaria entre la formación académica formal en filosofía con el hecho de convertirse en un filósofo. O para formular esta idea de otro modo, habría que decir un profesional de la filosofía no es necesariamente un filósofo. Si bien es cierto, por otra parte, que no se encuentran reñidas la tradición académica con la posibilidad de llegar a ser un filósofo, en lo concreto es que no hay una relación de expresa necesidad entre ser un filósofo y su vinculación -en un caso más o en otro menos- con la academia. Casos para ejemplificar esta cuestión hay muchos. Me permito ofrecer sólo tres: el primero sería el propio Gramsci que, como hemos indicado, cursó estudios de lingüística en la Universidad de Turín y, sobre el cual, a menos que exista mala fe, difícilmente no se le pueda considerar dentro de la tradición filosófica y por lo mismo como un filósofo. Bajo el siguiente convencimiento me permito afirmar que la condición de un filósofo no se encuentra determinada -a priori- por la garantía de su profesionalidad. No hay filósofo profesional, la universidad no da la condición de filósofo a través de una titulación profesionalizante. A lo sumo, como ironiza el filósofo chileno Patricio Marchant en Sobre árboles y madres, podrá dispensar una titulación que nos permita llegar a ser "profesores de filosofía" ${ }^{16}$. Pero eso es, como sabemos, otra cosa. La filosofía se encuentra, en muchos casos, fuera de su exclusiva regimentación o potestad. El otro caso, quizás más emblemático aún, sería el de Nietzsche. Acá la comparación con Gramsci en cierto punto puede llegar a ser odiosa, porque sabemos que Nietzsche llegó incluso a ejercer docencia universitaria. Y, sin embargo, su formación profesional fue la de un filólogo. Y nada de eso pone en cuestión su condición de filósofo. Y sin ir más lejos, y observando un caso aún más canónico, como sería la figura del propio Descartes, quien era de formación jurídica e influyó en el desarrollo de las matemáticas.

\section{I. Gramsci: filósofo y filosofía de la praxis}

Si hay un cometido que distingue de modo específico la labor de los

I5 A. SANTUCCI. Gramsci... p. 4I.

I6 P. MARCHANT. Sobre árboles y madres. La Cebra: Buenos Aires, 2009, p. Io8.

Palabra y Razón ISSN 24524646 versión en línea No 20 Diciembre de 202I 
filósofos ese sería sin duda su vocación por la destrucción de prejuicios. Gramsci en Apuntes para una introducción y una iniciación en el estudio de la filosofía y de la historia de la cultura arremete con especial encono sobre aquel maximizado prejuicio que sostiene que la filosofía es una cuestión difícil y que esa misma dificultad lleva a que se convierta en asunto al que se dedican una "determinada categoría de científicos especialistas o de filósofos profesionales y sistemáticos" ${ }^{\text {"7 }}$. Prejuicio de una seriedad que genera una distancia de los asuntos más mundanos y que exigen una atención a partir de la inmediatez, prejuicio que alienta de manera -hasta cierto punto injusta- aquella la idea que los dedicados a la filosofía sólo se preocupan de cuestiones que parecen escapar a la contingencia. Sin duda que Gramsci se siente interpelado ante esta situación y no queda cruzado de brazos. Propone pensar las cosas desde una perspectiva distinta, esto es, invirtiendo los factores. Esto significa, que la filosofía no es una actividad a la que dedican algunos, sino que es, sobre todo, algo en lo cual, seamos conscientes o no, ya estamos involucrados. Eso quiere decir, en la lógica gramsciana, que todos los humanos somos filósofos. Reflexión que, según nos parece, se encuentra en la misma sintonía de los propuesto por Aristóteles en la Política cuando afirma que los humanos (ánthropos) somos por naturaleza (físis) sujetos políticos (zoon politikon) ${ }^{18}$. De tal forma que, siendo sujetos políticos, somos en la misma medida, y por ello mismo, sujetos a quienes lo filosófico no puede dejar de interpelarnos de manera inexorable puesto que la filosofía se encuentra alentando el sostén de lo público. No somos ajenos a la filosofía, porque la política es parte de nuestra naturaleza y, es justamente a partir de ahí, que la organización del espacio público y la construcción del sentido del mundo alcanza ese rasgo distintivo que permite hacerlo habitable. La estrategia para enfrentar la hegemonía de ese prejuicio, aunque pueda parecer sencilla no por nada resulta profundamente efectiva. Consiste en combatir la falsa idea que el desarrollo de la actividad filosófica es algo le corresponde, de manera preferente y exclusiva, a algunos pocos debido a ese alto nivel de abstracción lógica. Muy por el contrario, sostiene que no hay ningún ser humano que pueda escapar a su imperio, incluso cuando éste no sea consciente de ello. En tal caso, conviene tener presente como afirma Gramsci, que "se puede decir que la mayor parte de los hombres son filósofos, en cuanto actúan prácticamente y su actuar práctico (las líneas directrices de su conducta) contiene implícitamente una concepción del mundo, una filosofía"19. En resumen, su estrategia consiste en destruir la inercia que sostiene esa falsa idea, para abonar en

I7 A. GRAMSCI. Introducción a la Filosofía de la praxis... p. 3.

I8 ARISTÓTELES. Política. Gredos: Madrid, 2007, p. 30.

I9 A. GRAMSCI. Antología... p. 422.

Facultad de Ciencias Religiosas y Filosóficas - Universidad Católica del Maule 
la consciencia de cada sujeto el dinamismo suficiente para hacerlo un actor de primera línea en la historia.

Aunque, claro está, esa 'filosofía' que comprende a todo el género humano tiene sus límites y características específicas que la circunscriben a una dimensión 'espontánea'. Dicha espontaneidad se sustenta, sin embargo, no es sí misma ni en el a cada quien. Sino en algo así como el continente contextual (paradigma) del que se nutre, a su vez: del lenguaje, el sentido común y la religión popular y el sistema de creencias, supersticiones, opiniones, modos de ver y actuar ${ }^{20}$ que dan origen a una determinada concepción del mundo (weltanschauung) que ha sido aceptada e impuesta de manera mecánica y que en términos gramsciano se entiende como ideología. ¿De qué modo ha sido impuesta esta ideología de la clase dominante? Pues, de la única forma posible, esto es, socialmente. De un modo mucho más distinguido, José María Laso sostiene, a propósito de lo que hemos venido mostrando, que "mediante los aparatos ideológicos constituidos por los medios de comunicación, la educación y enseñanza, la Iglesia, las Fuerzas Armadas, etc., lo que permite a la clase dominante soldar en torno a sí un bloque de fuerzas sociales diferentes" ${ }^{21}$.

Siendo esto así, es preferible, sostiene Gramsci, pasar el momento de la crítica y de la conciencia la que nos permitiría participar de manera activa de la construcción del mundo y no ser meros espectadores. En tal caso, es razón suficiente para explicar por qué el filósofo debe preocuparse por el presente, la historia y la cultura. Entender adecuadamente a Gramsci implica atender a esta relación entre filosofía e historia, o entre teoría y práxis. Pero sobre todo comprender que la pretensión de fuerza que posee una filosofía de la praxis radica sustancialmente en su función de contrapeso hegemónico, un mecanismo que articularía una suerte de síntesis crítica que alcanza su consumación en el momento de la producción de una conciencia política.

Teniendo en cuenta esta condición, es que podemos comenzar a intuir la importancia explícita que tiene esta necesidad gramciana de reformular del estatus del filósofo y la filosofía. Contrariamente a lo que 'el sentido común' supone, quizás desdibujadamente-, es que el filósofo oficia en y desde un espacio paralelo a las urgencias que demanda el presente, entregándose a la cómoda meditación de entidades universales e intemporales. Esto es, como ya hemos insistido, alejado del tiempo

20 A. GRAMSCI. Introducción a la Filosofía de la praxis... p. 3.

2I "Vigencia del pensamiento de Gramsci" en El Basílisco. 6 (1979), pp. 73-83, p. 77. 
presente, y sus reflexiones, por tanto, poco o escasamente tendrían que ver con las correspondencias de su tiempo histórico. Este supuesto, ya con cualquier lectura que se aproxime a Algunas cuestiones sobre la cuestión meridional por muy básica que ella sea, inmediatamente hace saltar por los aires ese mal supuesto entendido en el cual la filosofía se encuentra reñida con la actualidad. Habría que asumir a Gramsci como un filósofo particular en tanto en cuanto es este un pensador y activista político que se toda reflexión es parasitaria de su tiempo. Insisto e insistiré, casi hasta la saciedad, en este asunto. Se puede entonces ilustrar la fisonomía de Gramsci como un filósofo que tiene por vocación oficiar en la plaza pública.

Nos preguntamos entonces, ¿por qué resulta tan importante intervenir en la historia? Fundamentalmente porque no hay nadie quien pueda restarse. Y la mejor forma de sumarse en ese proyecto sería a través de una manera activa, esto es, crítica. ¿Cómo sería posible aquello? Pues cargando los dados de la historia, podríamos decir, con el interés de un proyecto común que haga la diferencia y que contrarreste la vida inercial que se hace carne en la indiferencia que las más de las veces adopta la forma de la apatía, en otras del parasitismo y las más de las veces como cobardía, en resumen, una forma de no vida. Siendo así el caso, hemos de ser conscientes que "La indiferencia opera con fuerza en la historia. Opera pasivamente, pero opera" ${ }^{22}$. La falta de consciencia opera de una manera silenciosa, de modo específico que lo teórico, es decir, aquel proyecto o propósito se encuentra ausente. En tal caso, "El hombre-masa activo opera prácticamente, pero no tiene una clara conciencia teórica de su obrar" 23 lo que reviste un peligro latente.

El diagnóstico muestra que si hay un 'sentido común' eso se debe a que determinadas fuerzas e intereses reaccionarios han ido, con el paso del tiempo sedimentando razones o puntos de vista en las masas populares. De ahí que el sentido común opera como una filosofía, como un modo de entender y explicar esto que llamamos 'la realidad'. Gramsci tiene plena consciencia que la osificación de estas formas de entender las cosas, cuando menos en lo que refiere al mundo occidental, la tradición cristiana ha jugado un papel máximamente importante. Y ante esa situación ve como fundamental oponer una fuerza de igual o mayor magnitud que pueda contrarrestar los efectos inerciales que hasta entonces nuestra cultura sufre. Es así que Gramsci propone en su reflexión la noción de la filosofía de la praxis, que es una suerte de

22 A. GRAMSCI. Odio a los indiferentes. Ariel: Madrid, 20II, p. I9.

23 A. GRAMSCI. Introducción a la Filosofía de la praxis... p. 15. 
filosofía de la acción, esto es, un tipo de filosofía que toma posición en este tablero político. Siendo así, es que se entiende que, para éste, en lo fundamental "La posición de la filosofía de la praxis es antitética a la católica: la filosofía de la praxis no tiende a mantener a las 'gentes sencillas' en su primitiva filosofía del sentido común sino que quiere conducirlas a una concepción superior de la vida"24. Esto quiere decir, que nos lleva desde el estadio inercial del sentido común hacia el buen sentido, esto es, el momento del posicionamiento crítico.

La idea de que la filosofía se convierta en una praxis, una práctica, ello no significa un repliegue a un lúcido desencanto elitista ni en una hipertrofia criticista, sino que debe conducirnos a afinar críticamente nuestras posiciones y a disponernos a una articulación orgánica de las masas que será, al menos en un primer momento, orientado por ese nuevo tipo de intelectual, que bajo la gramática gramsciana se comprende con el nombre de un intelectual orgánico. ¿Por qué resulta necesario un intelectual de este tipo? Fundamentalmente porque, como profesa Gramsci, "Una masa humana no se distingue y no se hace independiente 'por sí misma' sin organizarse (en sentido lato), y no hay organización sino intelectuales, es decir sin organizadores y dirigentes, o sea, sin que el aspecto teórico en el nexo teoría-práctica se distinga concretamente en un estrato de personas 'especializadas' en la elaboración conceptual y filosófica." ${ }^{25}$. A razón de los cual, como nos lo hace notar el filósofo Germán Cano, "La filosofía de la praxis por tanto, no se propone como ningún gesto de repudio a la herencia filosófica, sino como un gesto de fastidio frente aquellos filósofos que, con sus reiteraciones, no comprenden la necesidad de afirmar una relación entre teoría y práctica" ${ }^{26}$.

Debemos reparar en esto: en Gramsci el proyecto de una 'filosofía de la praxis' surge como una tentativa experimental de reformular la célebre undécima tesis sobre Feuerbach, que, como bien se recordará, reza del siguiente modo: "Los filósofos sólo han interpretado de diversas maneras el mundo, pero después de eso importa transformarlo" ${ }^{27}$, pero en un contexto histórico en el que empieza a ser problemática la tesis del joven Marx de que basta con ser 'conscientes' del sueño de la realidad para 'realizarlo' en el mundo. Esto es, en una situación de crisis

\footnotetext{
24 A. GRAMSCI. Introducción a la Filosofía de la praxis... p. 15.

25 A. GRAMSCI. Introducción a la Filosofía de la praxis... p. I7.

26 G. CANO. "Epílogo. Una filosofía para su presente" en M. RÍOS. Reflexión mínima: Cenaltes: Viña del Mar, 20I8, p. I08.

27 K. MARX. "Tesis sobre Feuerbach" en O. FERNÁNDEZ-DÍAZ. De Feuerbach al materialismo histórico.
} 
del concepto de 'realización' histórica. En tal sentido, tal como lo hace sentir Fernández Buey, "Gramsci adopta un punto de vista original" al negar la corriente predominante del materialismo histórico que sostiene la existencia necesaria de leyes históricas de carácter absoluto. Una corriente que también es conocida como 'marxismo mecanicista'. De ahí que propusiera, insiste Fernández Buey, que "todo fenómeno histórico tiene carácter individual o particular y que, por tanto, tiene que ser estudiado en su concreción; afirma que el desarrollo histórico se rige por el ritmo de la libertad"28.

La superación de la brecha entre el ser social y la conciencia ya no viene garantizada por la Historia planteada con mayúsculas. Y si no hay ya correlación entre la tarea política encomendada y el agente social, tampoco podemos decir que la realidad sólo se plantea las preguntas que puede responder. En esta situación, como se puede comprender, es la que se encuentran los consabidos "filósofos académicos", esos filósofos especialistas de una ínfima -y entre más ínfima mejor-, particularidad de un determinado autor, época filosófica u obra.

En aquella recordada entrevista de Louis Althusser concedida a principios de enero de 1968 (año, por cierto, emblemático para el siglo XX) a María Antonieta Macciocchi para el diario L'Unitá, y que se puede encontrar fácilmente en el libro Para leer El Capital. Contrario esta especie de filósofo y filosofía nos advierte que "la gran tesis de Marx, Lenin y Gramsci: la filosofía es el fundamento de la política”. En líneas simples, Althusser lo sintetiza bajo la siguiente fórmula que "la filosofía es la lucha por las palabras"
¿Por qué la filosofía pelea por palabras? Las realidades de la lucha de clases son 'representadas' por 'ideas', las que a su vez son representadas por 'palabras'. En los razonamientos científicos y filosóficos, las palabras (conceptos, categorías) son 'instrumentos' de conocimiento. Pero en la lucha política, ideológica y filosófica las palabras son también armas: explosivos, calmantes o venenos. Toda la lucha de clases puede, a veces, resumirse en la lucha por una palabra, contra otra palabra ${ }^{29}$.

En este diagnóstico de Althusser, en sintonía evidente con el pensamiento de Gramsci, reconoce -para estos tiempos del Capital- la

28 F. FERNÁNDEZ-BUEY. Leyendo a Gramsci... p. 99.

29 L. ALTHUSSER. Para leer el Capital. Siglo XXI: México, 20I2, p. II.

Facultad de Ciencias Religiosas y Filosóficas - Universidad Católica del Maule 
necesidad de una nueva filosofía. Una filosofía que pueda intervenir en su coyuntura, porque forma parte inevitable de esa coyuntura que acontece en el proceder de la política. Si esto es efectivamente cierto, entonces, la filosofía ha de lidiar por las palabras. Pero para Gramsci, aunque una acción transformadora no puede dejar de ser una 'teoría', una 'filosofía', también es un discurso que se arriesga a decir lo que pasa $y$, en esa medida, organiza la realidad; una palabra que desea realmente el deseo de la realidad, o que desea con el mismo deseo que la realidad.

La filosofía ha de tratar, quiéralo o no, con el estado presente de las cosas. Se encuentra, por tanto, contaminada y exigida por los acontecimientos de su momento histórico. En esto hay una relación de fuerzas recíprocas. El filósofo interfiriendo en su realidad histórica inmediata y ésta, a su vez, en el decurso de sus propuestas. El filósofo, así como todo actor o actriz con vocación por la inmanencia del presente, no puede sino ser un sujeto político.

Entonces, ya no puede parecer 'rara', 'extraña' o 'anómala' la experiencia de una teología y una filosofía de la liberación desarrollada en latinoamericana a principios de la década de los 70 del siglo XX. Ni que las propuestas teóricas de Paulo Freire, por ejemplo, que datan de los años 60 del mismo siglo XX (estoy pensando ahora mismo en $\mathrm{La}$ educación como práctica de la libertad, de I964) contengan en algún sentido, y al menos germinalmente, un guiño a Gramsci, sin ser, necesariamente, deudoras plenas del pensador sardo.

\section{3. ¿Qué entender por eso de la meridionalidad?}

Anteriormente habíamos citado una carta que Gramsci había dirigido a su cuñada Tatiana Schucht. En ella, recordaremos, que entendía esto de la meridianidad como una investigación de la formación del público en Italia y cómo los intelectuales contribuyeron a eso. Pero Gramsci también nos aporta en otros escritos algunos elementos que nos permiten hacernos con una idea más acabada. Tengamos presentes que, en los primeros párrafos de La cuestión meridional, afirma que "La sociedad meridional puede definirse como una gran disgregación social (...) La sociedad meridional es un gran bloque agrario constituido por tres estratos sociales: la gran masa campesina amorfa y disgregada, los intelectuales de la pequeña y mediana burguesía rural, los grandes 
propietarios terratenientes y los grandes intelectuales"30.

Sobre el punto de la Meridionalidad hay que hacer varias consideraciones que resultan necesarias para su comprensión, más aún, habiéndonos ya pronunciado en torno a la condición particular que parce ocupar Gramsci en tanto es un filósofo nuevo, esto es, un filósofo de la praxis. En estas reflexiones convergen la acción y teoría. Pero también la nueva filosofía que comprende la íntima e indisoluble génesis entre historia y filosofía, esto es, su síntesis: política.

En tal sentido Gramsci afirma que:

\begin{abstract}
"La filosofía de una época no es la filosofía de tal o cual filósofo, de tal o cual grupo de intelectuales, de tal o cual división de la masa popular; es una combinación de todos los elementos que culmina en una determinada dirección, y cuya culminación se transforma en norma de acción colectiva, es decir, se vuelve histórica concreta y completa (integral). La filosofía de una época histórica no es pues otra cosa que la 'historia' de aquella, no es otra cosa que la masa de variaciones que el grupo dirigente ha logrado determinar en la realidad precedente: historia y filosofía son inescindibles en este sentido, formando un 'bloque'31.
\end{abstract}

Debemos tener a bien considerar que esta discusión denominada como La cuestión meridional, no es algo que Gramsci se halla inventado ex nihilo. De esta manera el texto como tal, significa una puesta en acción de la filosofía de la praxis. En tal caso se diría que se encuentra alentada por el deseo de explicar el cómo es que se ha construido y sedimentado el sentido común en las clases populares de la Italia del momento y que se inscribe dentro de una larga tradición que, como bien lo entiende García Bonafe, atraviesa todo el siglo XIX.

Los 4 autores citados por García Bonafe (Villari, Sonnino, Franchetti y Fortunato) forman parte de un grupo adscrito a la doctrina liberal, nunca se presentaron como una alternativa global, sin embargo, dieron a su programa un alcance político más amplio que el de los meridionalistas anteriores.

Es tremendamente significativo que La cuestión meridional sea un

30 A. GRAMSCI. Antología... p. 193.

3I A. GRAMSCI. Antología... pp. 422-423.

Facultad de Ciencias Religiosas y Filosóficas - Universidad Católica del Maule 
tema transversal al siglo XIX. Siglo en el que la unificación de Italia, entendida como el paso de una sociedad feudal a un Estado Liberal Burgués, que se proclamó en I86I en el Reino de Italia. Este proceso de Unificación en clave italiana se encuentra, a su vez, en una íntima comunión con la unificación de Alemania en clave prusiana. En I866 se firmó la Paz de Praga donde Veneto que se encontraba bajo el control de Austria pasa a quedar bajo control italiano. Estos dos son Estados Burgueses tardíos en su conformación, y singularmente, los dos Estados donde terminaron cobrando forma dos versiones del fenómeno del fascismo.

La dificultad del problema meridional se central en desequilibrio entre las dos zonas que parecen conformar la península, y en una de ellas, donde las injusticias sociales, el atraso cultural y económico galopaban a sus anchas. La tensión se da entre una sociedad industrial (Settentrione) el Norte [Val Aosta, Piamonte, Lombardía, Trentino, Veneto, Toscana, Umbria y Lazio] y una sociedad agrícola (Mezzogiorno) el Sur [Cerdeña, Sicilia, Calabria, Puglia, Campania y Abruzi].

Si el objetivo es llegar a gobernar la estrategia consistirá en el establecimiento de un sistema de alianzas y para Gramsci la clase llamada a liderar este cambio es el proletariado, siempre y cuando:

El proletariado puede convertirse en clase dirigente y dominante en la medida que consigue crear un sistema de alianzas de clases que le permita movilizar contra el capitalismo y el Estado burgués a la mayoría de la clase trabajador, lo cual quiere decir en Italia, dadas las reales relaciones de clases existentes en Italia, en la medida que consigue obtener el consenso de las amplias masas campesinas" (2003, p. 19).

Como sostiene Santucci, los acercamientos a la obra de Marx por parte Gramsci se pueden constatar desde muy temprano. Porque desde la época del liceo tenía conocimiento de los principios del Manifiesto de Marx. Prueba de ello serían "Las partes conclusivas de una composición escolar sobre el tema Oprimidos y opresores desarrollado en el tercer año del liceo" ${ }^{32}$.

En la posibilidad de una trasformación del campo político italiano

32 A. SANTUCCI. Gramsci... p. 36. 
en cuestión para inicios del siglo XX, el proletariado, según Gramsci, tiene una misión histórica, que no es otra que la de convertirse en clase dirigente, en tanto en cuanto es la única clase revolucionaria. Es la llamada a liderar, lo que el propio Gramsci denominará en Los cuadernos de cárcel 'La gran política'. Las clases subalternas, entre ellos los campesinos, artesanos, pequeños comerciantes etc., se corresponden con 'La pequeña política', del todo insuficiente para alcanzar el logro de un cambio radical. Pero sólo alcanzando una alianza con las clases trabajadoras, que según Marx son reaccionarias, pueden estas, siendo dirigidas por el proletariado, alcanzar el triunfo y desarrollar las bases para un nuevo Estado Socialista. Esta convicción de que el proletariado era el encargado de dirigir, y producir una alianza con las otras clases, provenía, muy seguramente, del conocimiento y lectura que había realizado del Manifiesto comunista. De ahí conviene tener presente la siguiente reflexión de Marx:

De todas las clases que hoy se enfrentan a la burguesía sólo el proletariado es una clase verdaderamente revolucionaria. Las demás clases decaen y perecen con el desarrollo de la gran industria; el proletariado, en cambio, es su producto más peculiar. (...) Los estratos intermedios, el pequeño industrial, el pequeño comerciante, el artesano, el campesino, todos ellos combaten a la burguesía para salvar de la ruina su existencia como tales estratos intermedios. No son, pues, revolucionarios, sino conservadores. Más todavía, son reaccionarios ${ }^{33}$.

Christine Buci-Glucksmann acierta notablemente cuando enfatiza -a propósito de la carta que envía para la fundación de L'Unità el I2 de septiembre de 1923- en el hecho que llamada 'cuestión meridional' en Gramsci no se queda simplemente en sujeto al aspecto de la necesaria alianza proletario-campesina, sino más bien en el hecho que ésta posee un alcance más amplio y que desemboca en la 'cuestión nacional'. "Gramsci muestra que la cuestión meridional no termina únicamente con el problema de la alianza obrero-campesina, porque ésta es también una 'cuestión territorial', y por lo tanto una cuestión nacional"34.

El proletariado tiene una misión histórica, al convertirse en clase dirigente, puesto que es la única clase revolucionaria. Es la llamada a liderar, lo que el propio Gramsci denominará en Los cuadernos de Cárcel

33 K. MARX - F. ENGELS. El Manifiesto del Partido Comunista... p. 6 o.

34 CH. BUCI-GLUCKMANN. Gramsci y el Estado. Siglo XXI: Madrid, I978, p. 199.

Facultad de Ciencias Religiosas y Filosóficas - Universidad Católica del Maule 
'La gran política', definiéndola como aquella política que “(...) comprende las cuestiones vinculadas con la fundación de nuevos Estados, con la lucha para la destrucción, la defensa, la conservación de determinadas estructuras orgánicas económicas-sociales"35. Distinguiéndole de las clases subalternas, entre los que se pueden encontrar a los campesinos, artesanos, pequeños comerciantes etc., y se corresponde a su vez con los rasgos de aquella 'pequeña política' que Gramsci entiende como “(...) las cuestiones parciales y cotidianas que se plantean en el interior de una estructura ya establecida por las luchas de preeminencia entre las diversas facciones de una misma clase política" 36 , un tipo de política que resulta del todo insuficiente para alcanzar el logro de un cambio radical respecto de lo que Marx y Engels caracterizan como elementos que distinguen la esencial del desarrollo de la sociedad burguesa, esto es, las relaciones de producción y las relaciones sociales en su conjunto ${ }^{37}$. De ahí se desprende el interés de las clases dominantes por lograr que este tipo de discusiones no alcancen el fondo de la estructura orgánica del Estado, puesto que, tal como lo explica Daniel Campione "Éste constituye un objetivo fundamental de las clases dominantes, empeñadas en reservarse con carácter exclusivo los aspectos estratégicos de la acción, aquellos que atañen a la estructura socia en su conjunto" ${ }^{38}$.

Pero sólo alcanzando una alianza con las clases trabajadoras, que según Marx son reaccionarias. Pueden estas, siendo dirigidas por el proletariado, alcanzar el triunfo y desarrollar las bases para un nuevo Estado Socialista. En palabras de Santucci, atendiendo a Gramsci, sostendrá que "Las clases subalternas apuntan a la conquista del poder político, pero el empuje de las necesidades económicas no basta para absorber esta misión histórica"39. Al proletariado, por tanto, le corresponde en derecho, en tanto en cuanto es una clase moderna, la misión histórica de convertirse en clase dirigente para desarrollar lo que Gramsci entiende como 'La gran política'.

En este punto de la exposición podemos colegir que se perfilan otras dos categorías claves para la filosofía de la praxis gramsciana, a saber: hegemonía y dominación. Conceptos que, muchas veces suelen ser utilizados como sinónimos, pero resulta conveniente no confundir.

35 A. GRAMSCI. Cuadernos de la Cárcel V. ERA: México, 1999, p. 20.

36 A. GRAMSCI. Cuadernos de la Cárcel... p. 20.

37 K. MARX - F. ENGELS. El Manifiesto del Partido Comunista... p. $5 \mathrm{I}$.

38 D. CAMPIONE. Leer a Gramsci. Continente: Buenos Aires, 20I4, p. 88.

39 A. SANTUCCI. Gramsci... p. 85. 
En tal sentido parece necesario señalar que en esta idea de intereses o necesidad de coincidencia de los intereses particulares de una determinada clase se esfuerce en hacerlas coincidir con los intereses generales, es en última instancia una estrategia de la clase dominante. A partir de la cual se genera una cosmovisión, esto es, un modo de entender las relaciones sociales -como algo connatural- y que se condensa bajo la forma del hábito o el sentido común. Como mecanismo de legalidad, validación.

Si tomamos como ejemplo el caso de Chile, habría que afirmar que, hasta el denominado estallido social de octubre de 20I9, era éste un país donde todas las formas posibles del descontento social eran imaginadas y administradas en forma connatural a las lógicas y políticas hegemónicas vigentes. Esto ocurre porque el poder hegemónico hasta ese momento había operado -y opera- a través del 'sentido común' haciéndonos creer el cambio se produce a partir de un sujeto social individual, cuando en rigor la transformación pasa, como sostiene Gramsci, a partir del accionar de un sujeto social colectivo (el proletariado).

En una entrevista realizada por Rodrigo Castro para el libro $\mathrm{La}$ irrupción del devenir, a propósito de cumplirse 40 años del mayo del 68, Jean Pierre Duteuil, quien fuera fundador del movimiento anarquista en la universidad de Nanterre sostiene una idea interesante de compartir: "La revolución es más necesaria que nunca. Lo cual no quiere decir, necesariamente, que sea posible" 40 . Una pregunta interesante de responder sería, por qué ésta no es posible. Al parece, al menos en Chile, un número importante de la población se ha visto expuesta durante varias décadas a condiciones de desamparo social de diversa índole, y sin tener la posibilidad de acceder a un trabajo que pueda dar para cubrir con lo mínimo para subsistencia material. El triunfo de lo que Gramsci entendía como la 'pequeña política' podría explicar en alguna medida esa administración eficiente del desencanto social en favor de las clases dominantes y el mantenimiento efectivo del status quo.

Los reivindicativos movimientos estudiantiles en el Chile de 20II, habría que afirmar, no fueron movimientos revolucionarios. Estas no apuntaban a la conquista del poder político, ni tampoco a la generación de una cultura contrahegemonía. (ni una cultura de alianzas con otros sectores sociales o de clases). Se encontraban, por el contrario, alentadas

4 J. P. DUTEUIL. "Entrever fugitivamente lo posible" en R. CASTRO - M. RÍOS (coord.) La irrupción del devenir. El mayo francés y la historia del tiempo presente. Universidad Católica Silva Henríquez: Santiago de Chile, 2009, p. 58. 
por un carácter puramente práctico -utilizó su sentido bajo una formulación más banal- esto es, orientados bajo el imperativo de una necesidad económica que busca su sobrevivencia y no por la imperiosa necesidad de un cambio de la totalidad de las condiciones de posibilidad de la vida en comunidad. Válida a todas luces, pero del todo insuficiente, si el deseo es un cambio de las estructuras que configuran la existencia.

Si los gobernados tienen confianza en los gobernantes se puede gobernar, se puede ejercer el poder, sin acudir a la coerción. Por el contrario, cuando la confianza se desvanece lo que tenemos es, en todo caso, dominación sin hegemonía. De ahí que sea importante que no se deba confundir los votos, o el actor del sufragio, con la hegemonía.

Si el objetivo es la conquista del poder y por consiguiente la transformación del Estado, la estrategia a desarrollar es una 'alianza' con otras clases sociales con un sentido de dirección cultural en la que, por cierto, al proletariado le corresponde desempeñar un rol direccional.

Para ser capaz de gobernar como clase, el proletariado tiene que despojarse de todo residuo corporativo, de todo prejuicio o incrustación sindicalista (...) tiene que pensar como obreros miembros de una clase que tiende a dirigir a los campesinos y a los intelectuales, como miembros de una clase que puede vencer y que puede construir el socialismo sólo si está ayudada y seguida por la gran mayoría de esos estratos sociales ${ }^{4 \mathrm{I}}$.

De este convencimiento se sigue, como señala Emilio Corbière, que "para Gramsci, en las sociedades en las sociedades occidentales, el cambio revolucionario sólo puede darse si se lucha por la hegemonía social y cultural. Esa hegemonía se desarrolla cuando las clases oprimidas despliegan su propia concepción del mundo y obtienen para ella el 'consenso activo' de otras clases y capas sociales" ${ }^{22}$. Si el proletariado, como señala Marx, es una verdadera clase revolucionaria (por tanto, moderna), lo es en derecho propio porque es el producto más peculiar del capitalismo. Del mismo modo podría extenderse este razonamiento en orden a explicar las características del nuevo intelectual moderno (revolucionario) en tanto en cuanto, es éste -también-, un producto peculiar del capitalismo y, por tanto, el único capaz de responder a las

4I A. GRAMSCI. Antología... p. 193.

42 E. CORBIÈRE. "Antonio Gramsci" en CEME. Centro de estudios Miguel Enríquez. Archivos Chile. (s.f.). Disponible en: http://www.archivochile.com/Ideas_Autores/gramscia/s/gramscisobreoo02. pdf 
demandas históricas de transformación.

La tipología del intelectual que le interesa a Gramsci, esto es, aquel que se puede encontrar a la altura de los tiempos para la transformación de los social, aportando a las condiciones subjetivas no es ni 'el viejo intelectual' que tiene predominio en la sociedad agrícola ni tampoco esa segunda clase de intelectual vigente en su momento histórico que ha sido producido por la industria, el "organizador técnico, el especialista de la ciencia aplicada" ${ }^{43}$. No les interesa, ni uno ni otro, porque, al igual que Benedetto Croce, a decir de Gramsci, estos han impedido la radicalización de la masa campesina a través de consumación de una forma de entender el mundo (Lebenswelt) que se manifiesta bajo la forma del 'sentido común'. La generación de un nuevo intelectual, acorde con los tiempos, un intelectual de la praxis, será capaz de producir, en cambio, un 'buen sentido'. Una disposición crítica en alianza con el segmento popular.

cc) () (2) Esta obra está bajo una licencia de Creative Commons

Reconocimiento-No-Comercial-Compartir Igual 4.0 Internacional.

43 A. GRAMSCI. Antología... p. 195.

Facultad de Ciencias Religiosas y Filosóficas - Universidad Católica del Maule 